\title{
5-FITC-labeled Gl-heptapeptide
}

National Cancer Institute

\section{Source}

National Cancer Institute. 5-FITC-labeled Gl-heptapeptide. NCI Thesaurus. Code C97659.

A radioconjug ate consisting of the 7 amino acid peptide sequence ASYNYDA (GI heptapeptide) and labeled with the fluorescent dye fluorescein isothiocyanate (5-FITC), with potential imaging activity. Upon topical application to the esophageal mucosa using a spray, the heptapeptide moiety of 5-FIT C-labeled GI-heptapeptide binds to abnormal cells in the esophagus; the FITC moiety allows for imaging with white light and the area of interest for biopsies can then be visualized. 